\title{
Democracia e a ecologia complexa das redes sociais online: um estudo sobre discussões acerca do racismo e da homofobia
}

\section{Rousiley Celi Moreira Maia}

Doutora; Universidade Federal de Minas Gerais rousiley@gmail.com

\section{Thaiane Alexsandra Silva Rezende}

Mestra; Universidade Federal de Minas Gerais thaiaze@gmail.com

\section{Resumo \\ Este artigo tem por objetivo examinar a ecologia complexa da comunicação em diferentes ambientes online. Enquanto a maioria dos estudos sobre a comunicação digital investiga plataformas ou fóruns particulares, este estudo examina a repercussão de um evento controverso - expressões racistas e homofóbicas do Deputado Jair Bolsonaro no Programa CQC - em três ambientes: YouTube, blogs e Facebook. A análise explora como os cidadãos, mediante a conversação online diária, trocam suas opiniões e perspectivas, negociam o valor e o tratamento que dispensam uns aos outros. Os resultados revelam as características do conflito social concernente às regras de convivência cívica nessas diferentes plataformas, com recursos e dispositivos próprios, com expectativas de interação distintas entre os usuários e com públicos específicos.}

\section{Palavras-chave}

Deliberação. Racismo. Homofobia. Blog. Facebook. YouTube.

\section{Introdução}

A conversação entre os cidadãos - nas esferas privadas e públicas - acontece de modo profundamente complexo em situações contemporâneas. 0 uso das redes sociais online alterou dramaticamente a infraestrutura da conectividade social e tornou o ambiente político 
mais poroso. Tomando como inspiração a chamada "abordagem sistêmica da deliberação" (MANSBRIDGE et al., 2012; MAIA, 2012), este artigo tem por objetivo examinar a ecologia complexa da comunicação em diferentes ambientes online. Para tanto, investigamos um episódio que teve grande repercussão nos fóruns e nas redes sociais online: a declaração do deputado federal Jair Bolsonaro, que associou a paixão por uma mulher negra com promiscuidade, ao responder a uma questão apresentada pela cantora negra Preta Gil, durante o programa televisivo CQC.

Este episódio apresenta-se como um caso relevante para o propósito deste estudo por, pelo menos, duas razões. Primeiro, o caso permite explorar a chamada "ecologia complexa" da Web 2.0 (PAPACHARISSI, 2010; WALTHER et al., 2011; MAIA, 2014), a fim de dar a ver a especificidade de diferentes plataformas, com recursos e dispositivos próprios; com expectativas de interação distintas entre os usuários e com públicos específicos. De modo geral, os estudos sobre conversação ou debates em fóruns ou em redes sociais online são conduzidos em uma plataforma isolada ou em um único ambiente. Uma abordagem de diferentes redes sociais online é importante para: a) expandir a escala de análise para tratar da conexão entre distintos padrões comunicativos existentes em diferentes ambientes, tendo em vista as oportunidades e os constrangimentos de seus dispositivos tecnológicos; b) compreender as inter-relações que se estabelecem entre ambientes virtuais singulares, bem como entre seus usuários e públicos, dentro do processo comunicativo social mais amplo.

Em segundo, a análise da conversação espraiada nas redes sociais online, integrada de modo cada vez mais complexo ao dia a dia, é importante para revelar as diversas formas através das quais os cidadãos processam desentendimentos morais e conflitos de interesse. Esta perspectiva é relevante para os estudos da Comunicação Política porque os cidadãos, mediante a conversação diária, trocam suas opiniões e perspectivas, negociam o valor e o tratamento que dispensam uns aos outros, disputam a relevância dos acontecimentos tendo em vista suas afiliações e diferenças, e definem o que querem para si e para os outros. 0 presente estudo aborda conflitos sociais concernentes às regras de convivência cívica. Sabese que a conversação diária não pode ser completamente purificada de expressões intolerantes e ofensivas, uma vez que esta frequentemente escapa ao controle legal e ao controle político do constrangimento público. Muitos teóricos (GALEOTTI, 2002, p. 153; FORST, 2007, p. 237) esperam que a resposta a este problema seja buscada dentro da própria sociedade civil, na medida em que os cidadãos se eduquem mutuamente e, eventualmente, estabeleçam códigos de conversação não discriminatórios. Por isso, torna-se importante exami- 
nar empiricamente como as pessoas espontaneamente lidam com casos que envolvem intolerância, racismo e homofobia em diferentes ambientes digitais.

Este artigo está organizado da seguinte maneira. Na primeira parte, caracterizamos brevemente o episódio "Preta Gil e Bolsonaro". Nas três seções seguintes, examinamos a interação comunicativa que se deu em torno desse episódio em três ambientes da Web 2.0: a) um domínio genérico que pode abrigar qualquer tópico ou tema, i.e, o YouTube; b) um domínio destinado à interpretação e discussão personalizada de episódios, i.e, blogs; c) um domínio destinado à conversão em tom pessoal, prevalentemente entre pessoas conhecidas, i.e, o Facebook.

\section{Evento Preta Gil e Bolsonaro nas Redes Sociais Online}

Em 28 de março de 2011, o programa televisivo "CQC", com grande audiência da emissora Band, apresentou o quadro intitulado "0 povo quer saber". Na ocasião, perguntas sobre temas polêmicos foram feitas ao deputado Jair Bolsonaro, como a homossexualidade e a paixão por uma negra. A cantora Preta Gil perguntou ao deputado: "Se seu filho se apaixonasse por uma negra, o que você faria?". Bolsonaro, que é um ex-militar conhecido por seus valores de extrema direita e por suas causas anti-progressitas, respondeu: "Preta, não vou discutir promiscuidade com quem quer que seja. Eu não corro esse risco, e meus filhos foram muito bem educados e não viveram em um ambiente como, lamentavelmente, é o teu".

Na madrugada após a exibição do quadro, Preta Gil postou mensagens em seu Twitter expressando indignação: "advogado acionado, sou uma mulher Negra, forte e irei até o fim. Racismo é crime! E ele assume que o é. Conto com o apoio de vocês e na realidade vamos agradecer ao CQC que nos deu a prova maior" (GIL, 2011, doc. eletrônico). As declarações, proferidas num ambiente com grande visibilidade, a televisão, passaram a ser amplamente comentadas na internet. Na manhã do dia seguinte, Jair Bolsonaro manifestou-se publicamente. Em entrevista à seção Terra Magazine, o deputado disse não ter entendido corretamente a pergunta.

Eu entendi que ela me perguntou o que eu faria se meu filho namorasse um gay [...]. Se eu tivesse entendido assim, eu diria: 'meu filho pode namorar qualquer uma, desde que não seja uma com o teu comportamento'. Se eu fosse racista, eu não seria maluco de declarar isso na televisão (ROCHA, 2011, doc. eletrônico).

Ciente de que racismo é considerado crime no Brasil, Bolsonaro buscou se eximir da imputação de racismo, mas manteve seu posicionamento contrário ao relacionamento afeti- 
vo entre pessoas do mesmo sexo, em tom homofóbico. 0 deputado é um dos principais opositores à união civil homossexual no Brasil e já havia declarado, em outro programa de TV, que os filhos tornam-se homossexuais por "falta de porrada".

0 caso teve ampla repercussão também nos media tradicionais, alternativos e independentes. A Ordem dos Advogados do Brasil anunciou a abertura de processo por quebra de decoro parlamentar contra o deputado e o advogado da cantora Preta Gil entrou com representação no Ministério Público por crime de intolerância racial e, ainda abriu um processo civil. Além disso, o episódio provocou um movimento denominado "Evento Fora Bolsonaro" no Facebook, com 43.808 adesões.

Para desenvolver um estudo exploratório sobre os debates acerca deste episódio, examinamos três ambientes digitais:

a) o YouTube e a página que dá acesso à visualização do vídeo que foi exibido pelo "CQC" (BOLSONARO..., [2011]), com 672 comentários;

b) o blog feminista "Escreva Lola Escreva" (ARONOVICH, 2011) com 48 comentários e o blog "Papo de Homem” (MARQUES, 2011), destinado ao público masculino, com 194 comentários;

c) o Facebook; com o movimento denominado "Evento Fora Bolsonaro" (FACEBOOK, 2011b) com 159 postagens e a página Jair Bolsonaro (FACEBOOK, 2011a) descrito como uma comunidade não oficial, com 610 comentários, o que equivale ao total de postagens datadas do dia 31 de março de 2011.

Realizamos uma análise qualitativa, iniciada por uma exploração preliminar de todos os posts. Na fase de seleção, extraímos da totalidade das postagens os comentários que tratavam dos temas de raça, gênero e/ou orientação sexual, ou de Preta Gil e Jair Bolsonaro. Na sequência, analisamos comparativamente os comentários selecionados, a fim de identificar as principais formas de abordagem. Para interpretar a natureza da comunicação e da interação entre os usuários nos ambientes virtuais, orientamo-nos por certos princípios que fundamentam a deliberação - tais como respeito ao conteúdo dos proferimentos e aos parceiros da interação, justificação dos proferimentos e reciprocidade (BÄCHTIGER et al., 2010; HABERMAS, 1996; KIES, 2010). Neste trabalho, não fazemos codificações sistemáticas desses elementos. 


\section{YouTube}

Em desafio ao tradicional monopólio dos media comerciais na produção e circulação de informação, o YouTube permite que diversos atores sociais se tornem produtores de media, radicalizando a ideia de que os cidadãos, com reduzida expertise, podem ter "suas próprias salas de redação" (JENKINS, 2009, p. 110). Sendo a plataforma mais popular atualmente para compartilhamento de vídeo, o YouTube permite que os usuários postem conteúdos livres de vídeo; visualizem o conteúdo postado por outros e façam comentários numa discussão em formato de rede. No espaço para expressão textual online do YouTube, os usuários interagem e estabelecem contato com outros usuários, geralmente pessoas desconhecidas (BOU-FRANCH; LORENZO-DUS; BLITVICH, 2012, p. 502). Aqueles que interagem neste ambiente têm muitas vezes em mente que estão diante de uma "massa de usuários ordinários imaginados" (BURGESS; GREEN, 2009, p. 8), sendo que muitos participam passivamente como observadores.

Diversos autores (BURGESS; GREEN, 2009, p. 6; HARTLEY, 2009, p. 133) destacaram a dupla função do YouTube como uma plataforma que opera tanto "de cima para baixo", para distribuir conteúdos produzidos por instituições políticas e organizações do mercado, incluindo as indústrias dos media tradicionais, quanto "de baixo para cima", para circular vídeos produzidos por organizações da sociedade civil, entidades e movimentos sociais, e cidadãos ordinários. Produções com lógicas distintas, advindas de atores sociais diferenciados, dotados das mais diversas motivações, se intersectam e se chocam neste ambiente plural.

A comunicação no espaço textual do YouTube permite tanto a participação seguindo a lógica "um-para-muitos" quanto a "discussão intra-grupo". Nesta plataforma, os participantes expressam visões plurais e conflitantes. Muitos participantes se identificam através de pseudônimos bizarros ("falomesmofoda-se", "Paudabarraca", "SendMelies"). Ao longo da sequência de comentários, nota-se, recorrentemente, a manifestação aberta de ofensas tanto ao conteúdo dos proferimentos dos outros quanto aos próprios participantes do fórum, através de expressões chulas, conforme se pode ver no Quadro 1: 
Quadro 1 - Comentários no YouTube

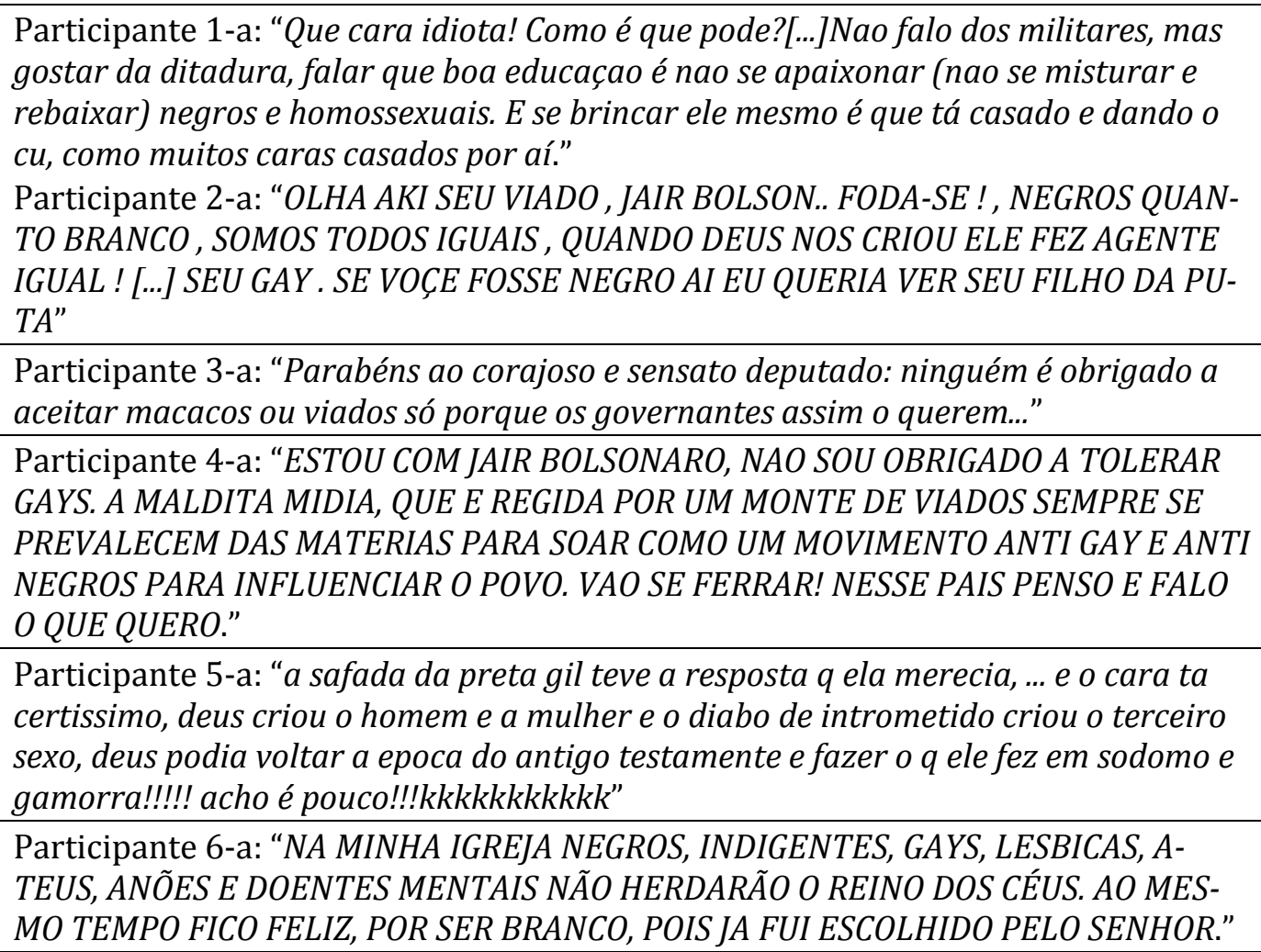

Fonte: APOCALYPSEFORFREE (2011, doc. eletrônico).

É possível notar que as pessoas encontram-se expostas à intolerância no YouTube, sendo este um terreno fértil para a afirmação do racismo e da homofobia. Ao invés de um "clube de cavalheiros", em que os cidadãos idealmente ponderam sobre suas preferências e negociam seus desentendimentos, tendo em vista algum tipo de acordo, observamos que o YouTube favorece a incivilidade e o desrespeito para com os oponentes (HILL; HUGHES, 1998; PAPACHARISSI, 2010; ROWE, 2014). Os usuários frequentemente enquadram suas objeções aos alegados ofensores com igual ausência de respeito. Mesmo aqueles que contestam contra diferentes formas de dominação e discriminação expressam ódio abertamente, como mostra o Quadro 2: 
Quadro 2 - Comentários no YouTube que contestam a discriminação

\begin{tabular}{|c|c|}
\hline Contestação & Expressão no espaço textual do YouTube \\
\hline $\begin{array}{l}\text { Contra a postura do deputa- } \\
\text { do e sua manifestação públi- } \\
\text { ca de preconceito e discri- } \\
\text { minação }\end{array}$ & $\begin{array}{l}\text { Participante 7-a: "disceminador do ódio, do racismo } \\
\text { e da homofobia! fora! foram posturas como a sua } \\
\text { que alimentaram massacres, assassinatos e sofri- } \\
\text { mento de gente de bem que só deseja respeito e feli- } \\
\text { cidade. fascista, hitleriano!" }\end{array}$ \\
\hline $\begin{array}{l}\text { Contra a posição de pessoas } \\
\text { e grupos que apoiam a pos- } \\
\text { tura do deputado e endos- } \\
\text { sam suas ideias }\end{array}$ & $\begin{array}{l}\text { Participante 8-a: "pelos comentários postados, se vê, } \\
\text { que o Brasil está onde está, porque idiotas elegem e } \\
\text { defendem idiotas como esse, como já disseram, o } \\
\text { povo tem o governo que merece, não me admira se } \\
\text { um imbecil desses um dia chegar a Presidente." } \\
\text { Participante 9-a: "O POVO QUER SABER: Essa mes- } \\
\text { ma gentinha que defende o Bolsonaro é o pessoal } \\
\text { que queria afogar nordestinos em Janeiro?Bateu a } \\
\text { dúvida." } \\
\text { Participante 10-a: "Eu não sei se tenho mais nojo } \\
\text { desse cidadão com mente coronelista, racista, retro- } \\
\text { grada, ou desses pré adolescentes fãs de restart que } \\
\text { concordam com ele nos comentários, pq não viveram } \\
\text { ditadura ou nunca passaram uma situação de dis- } \\
\text { criminação racial... Deixa eu ir ali vomitar!" }\end{array}$ \\
\hline $\begin{array}{l}\text { Contra a ofensa e o desres- } \\
\text { peito a minorias em nome da } \\
\text { liberdade de expressão }\end{array}$ & $\begin{array}{l}\text { Participante 11-a: “NÃO SOU HOMOSSEXUAL, MAS } \\
\text { PREFERIRIA SER HOMOSSEXUAL A SER O LIXO QUE } \\
\text { VOCÊ E ESSE SER ASQUEIROSO SÃO, INFELIZ! CON- } \\
\text { TINUEM A DEFENDER O DIREITO DE DESRESPEI- } \\
\text { TAREM NEGROS, HOMOSSEXUAIS, MULHERES E } \\
\text { MINORIAS PONDO A CULPA NA LIBERDADE DE EX- } \\
\text { PRESSÃO! CREIO NA LEI DO RETORNO, COVARDES! } \\
\text { CERTAMENTE CHEGARÁ O DIA DA COLHEITA DE } \\
\text { VOCÊS! CONTINUEM MESMO SEMEANDO A DIS- } \\
\text { CRIMINACÂO E O ÓDIO! É O QUE EU DESEJO PRA } \\
\text { VOCESS! ASSIM ME POUPAM O TRABALHO DE DESE- } \\
\text { JAR O MAL A VOCÊS, INÚTEIS! SEUS FILHOS DAS } \\
\text { PUTAS!” }\end{array}$ \\
\hline $\begin{array}{l}\text { Contra a discriminação, a } \\
\text { exclusão e a intolerância }\end{array}$ & $\begin{array}{l}\text { Participante 12-a: "Aí a gente aponta que quem diz } \\
\text { isso está sendo intolerante e homofóbico, e o mesmo } \\
\text { cara tem a PETULÂNCIA de dizer "ah, mas é a minha } \\
\text { opinião, você nâo tem nada com isso". } \\
\text { Pra começo de conversa: vai à merda. } \\
\text { Discriminação é CRIME. Não gostou? FODA-SE. } \\
\text { Gosta de ditadura? Vai pra Cuba." }\end{array}$ \\
\hline
\end{tabular}

Fonte: APOCALYPSEFORFREE (2011, doc. eletrônico).

A expressão agressiva anuncia o outro como um alvo de injúrias, ao invés de potenciais parceiros de conversação. Os atributos utilizados - "idiota", "imbecil", "palhaço", "veado" "gentinha" - marcam, de imediato, desigualdades entre os participantes e impedem que eles 
se engajem em uma cooperação dialógica para lidar com diferenças de valores, princípios e opiniões. Tem-se no YouTube uma "guerra de interpretações", para utilizar as palavras de Jeffrey S. Juris (2005, p. 416), com troca de ofensas feitas através do estilo "falo na sua cara". Neste ambiente, as trocas comunicativas sugerem uma sociedade dividida, em que as diferenças severamente restringem a possibilidade de diálogo.

\section{Blogs}

Blogs e mini-blogs (Twitter) operam de modo colaborativo. Usualmente definidos como plataformas para postagens regulares de informações e opiniões, os blogs apresentam frequentemente um tom pessoal. Apesar de apresentarem diferentes estruturas e propósitos, os blogs tendem a ser espaços para a reflexão sobre questões de interesse comum e para a expressão de opiniões. Análises quantitativas e qualitativas têm mostrado que os blogs são majoritariamente auto-referenciais (RECUERO; AMARAL; MONTARDO, 2009; RECUERO, 2010; PAPACHARISSI, 2010). A linguagem utilizada nesta plataforma, ainda que se conforme à linguagem ordinária, é reflexiva e com foco definido. Mesmo quando orientados jornalisticamente, os blogs se organizam através de tom pessoal e subjetivo, em contraste com os padrões mais convencionais de objetividade e imparcialidade jornalística. Os usuários normalmente se expressam tendo em mente o outro como uma "audiência" (KAYE, 2011, p. 210) e orquestram cuidadosamente a própria performance como num "púlpito público" (SCOTT, 20071 apud PAPACHARISSI, 2010, p. 145; TREMAYNE, 2007).

Em nosso estudo, selecionamos dois blogs: a) o "Papo de Homem", em que os participantes são majoritariamente homens, e b) "Escreva Lola Escreva", de orientação militante feminista, em que a autora do blog responde e comenta os posts (na seção "Fala gente fala"). Em ambos os blogs, nota-se claramente que os participantes apresentam uma reflexão ponderada sobre diversos "problemas" acerca do evento "Preta Gil e Bolsonaro". Diferentemente do espaço para expressão textual no YouTube, encontramos nos blogs um terreno mais favorável para que posições distintas, descordos morais e diferenças de interesses sejam negociados. Os usuários em ambos os blogs usualmente demonstram respeito aos seus potenciais parceiros de diálogo. Com isso, não queremos dizer que os usuários eliminem expressões carregadas de emoção, ressentimento, ironia, etc. Contudo, eles tendem a reconhecer reciprocamente o status igualitário do outro como uma fonte de razões e de reivindica-

\footnotetext{
${ }^{1}$ Scott. T. D. Analyzing political conversation on the Howard Dean candidate blog. In: Tremayne, M. (Ed.) Blogging, citizenship and the future of media. New York: Routledge, 2007. p. 39-58
} 
ções - o que permite equalizar as pressuposições sobre os parceiros de interlocução. Esta postura permite o engajamento discursivo com aqueles com quem se discorda.

Nesses ambientes, os participantes buscam comunicar uns aos outros as diferenças em suas definições da situação, fazer perguntas, dar sugestões e/ou propor recomendações. Alguns participantes buscam "corrigir" informações "falsas" ou visões tidas como "equivocadas" dos parceiros, o que, em alguns casos, desencadeia réplicas e tréplicas. A fim de ilustrar a troca argumentativa no blog, é útil reconstruir uma das principais polêmicas presentes no blog "Papo de Homem" em torno do que os usuários denominam "politicamente correto" versus a liberdade de expressão. Esta controvérsia se desdobra em disputas sobre questões morais, éticas e pragmáticas.

Em ambos os blogs, os participantes lançam argumentos bastante robustos e sofisticados no fórum público. Ainda que a interação não possa ser caracterizada como uma "discussão argumentativa" numa sequência linear, os participantes "se importam" em explicar suas proposições ou em justificá-las diante dos demais. Com o intuito de evidenciar a sofisticação das justificativas, mostramos, no Quadro 3, que os argumentos presentes no blog frequentemente encontram ressonância com argumentos utilizados no debate acadêmico sobre as questões em tela. Tratamos da sequência de apenas três posts no blog "Papo de Homem" sobre a referida querela acerca do "politicamente correto" e os conflitos sobre o que deve ser tolerado, por quais razões, e quais os limites aceitáveis para a restrição da liberdade de expressão.

Quadro 3 - Argumentos usados no blog "Papo de Homem"

\begin{tabular}{|l|l|}
\hline \multicolumn{1}{|c|}{ Linguagem no Blog } & \multicolumn{1}{|c|}{ Argumentos } \\
\hline Participante 1-b: "Já estou ficando de & A liberdade precisa de certas definições \\
saco cheio das pessoas criticando o poli- & para se caracterizar como não- \\
ticamente correto em defesa da liberda- & dominação (PETTT, 2003) e, assim, \\
de de agressão. Quer dizer, liberdade de & diferenciar-se do que o participante 1-b \\
expressão (Qual a diferença hoje em & chama de "liberdade de agressão". \\
\cline { 2 - 3 } dia?). & A liberdade de expressão é um princípio \\
Por mais que eu concorde que censura é & fundamental nas sociedades democráti- \\
algo que combina mais com a época da & cas. Contudo, se ela entra em choque e \\
ditadura militar, temos que reconhecer & viola outros princípios democráticos \\
que possuir liberdade de expressão não & (como o respeito à dignidade humana e \\
implica falar tudo o que queremos, na & a não-discriminação), a liberdade de \\
hora que queremos, da maneira que & expressão não deve ser tomada neces- \\
queremos & sariamente como um princípio superior \\
Eu realmente não vejo problema no poli- & ou prioritário (CITRON, 2010). \\
\cline { 2 - 2 } ticamente correto ... não passa de uma & Uma vez que a legislação considera ra- \\
tentativa de abrir os olhos da sociedade & cismo como crime, a não tolerância de \\
\hline
\end{tabular}


no que diz respeito a direitos básicos do ser humano (Não ser ostracizado por conta de sua cor, não ser atingido na cabeça com uma lâmpada fluorescente por ser gay, não ser rejeitado num emprego/bolsa de estudos por ser nordestino, etc)." termos considerados ofensivos deve também ser exercida pelos próprios cidadãos como uma forma de constrangimento social. (GALEOTTI, 2002, p. 138).

Fonte: MARQUES (2011, doc. eletrônico).

Com o propósito de contestar medidas de censura e auto-censura de discursos ofensivos, o post seguinte, apresentado no Quadro 4, afirma que a própria noção de grupos conduz ao segregacionismo; as políticas afirmativas comprometem a igualdade dos cidadãos, elas podem acentuar as desigualdades existentes na sociedade e podem, ainda, criar novas intolerâncias na sociedade.

Quadro 4 - Argumentos usados no blog "Papo de Homem"

\begin{tabular}{|c|c|}
\hline & os \\
\hline $\begin{array}{l}\text { Participante 2-b: "Não podemos ser sim- } \\
\text { plesmente pessoas, hoje somos nordesti- } \\
\text { nos, gays, índios, negros, motoboys, clas- } \\
\text { se média ... }\end{array}$ & $\begin{array}{l}\text { tamento igualitário às pessoas como } \\
\text { cidadãos. }\end{array}$ \\
\hline se média ... & $\begin{array}{l}\text { de dife- } \\
\text { smo, não } \\
\text { ferentes. } \\
\text { is, ao es- } \\
\text { eferenci- } \\
\text { oritários, } \\
\text { nembros }\end{array}$ \\
\hline $\begin{array}{l}\text { Criar leis es } \\
\text { 'minorias'; } s \\
\text { ria e nos de } \\
\text { mente somos }\end{array}$ & $\begin{array}{l}\text { As políticas de prote } \\
\text { tivas dirigidas a g } \\
\text { exacerbar, muitas } \\
\text { ção e o ódio social c } \\
\text { des beneficiárias (FR }\end{array}$ \\
\hline
\end{tabular}

Fonte: MARQUES (2011, doc. eletrônico).

Argumentos a favor da defesa do respeito à diferença dos cidadãos, como os do Participante 2-b, são, de modo geral, facilmente aceitos. Em grande medida, esses argumentos podem ser endereçados de maneira neutra (sem conteúdos específicos) e serem generalizados (dizendo respeito a todas as diferenças) (GALEOTTI, 2002, p. 138). Já argumentos a favor da restrição ou da coibição de atos tidos como ofensivos e danosos a grupos específicos, como os do participante 1-b, precisam ser mais complexos, já que entram em confronto com outros princípios, valores e direitos. Em sua resposta, o participante 1-b demonstra um cla- 
ro esforço para justificar sua posição a favor do tratamento especial às minorias, como se pode ver no Quadro 5.

Quadro 5 - Argumentos usados no blog "Papo de Homem"

\begin{tabular}{|c|c|}
\hline & \\
\hline $\begin{array}{l}\text { Participante 1-c: "A diferença é que o } \\
\text { índio apanha por ser índio, o gay apanha } \\
\text { por ser gay, o negro apanha por ser ne- } \\
\text { gro. Estou falando da violência "sem } \\
\text { justificativa". } \\
\text { Bater numa "pessoa urbana" (seja lá o } \\
\text { que você quis dizer com isso .... "pessoa } \\
\text { urbana" pode incluir: homossexuais, } \\
\text { negros, pobres, nordestinos, etc. etc. etc.) }\end{array}$ & $\begin{array}{l}\text { Por sofrerem uma "opressão estrutural" } \\
\text { (YOUNG, 2000), índios, negros e gays } \\
\text { são alvos de ofensa, exclusão e humilha- } \\
\text { ção sistemática. A ofensa a pessoas per- } \\
\text { tencentes a grupos vulneráveis e estig- } \\
\text { matizados é uma questão política e mo- } \\
\text { ral porque é um ato intencional motiva- } \\
\text { do pela identificação com a minoria } \\
\text { ("sem outra justificativa"). }\end{array}$ \\
\hline $\begin{array}{l}\text { não configura como algo menos pior que } \\
\text { bater numa minoria.... Se você realmente } \\
\text { acredita que "pessoas são somente pes- } \\
\text { soas", obviamente nunca pesquisou sobre } \\
\text { o assunto ou vivenciou uma situação. } \\
\text { Minorias existem independente de você } \\
\text { reconhecê-las ou não. Jogar a sujeira pra } \\
\text { baixo do tapete é muito conveniente, mas } \\
\text { também é utópico e não condiz com a } \\
\text { realidade. } \\
\text { Enquanto um problema não é resolvido } \\
\text { de forma definitiva, nada impede o go- } \\
\text { verno de tentar ajudar e consertar anos } \\
\text { e anos de desigualdade. As pessoas que } \\
\text { se opõem às leis de igualdade (sistema de } \\
\text { cotas, criminalização da homofobia, do } \\
\text { racismo, etc), mesmo que tais leis sejam } \\
\text { FALHAS,.... não pensam no bem da coleti- } \\
\text { vidade" }\end{array}$ & $\begin{array}{l}\text { Qualquer ato ofensa física ou verbal } \\
\text { deve ser condenada, mas não se deve } \\
\text { ser "cego" às diferenças de grupos es- } \\
\text { tigmatizados. Diferentemente da agres- } \\
\text { são dirigida às pessoas que gozam de } \\
\text { poder e prestígio social, a agressão en- } \\
\text { dereçada a pessoas pertencentes a gru- } \\
\text { pos subordinados não é fortuitamente } \\
\text { distribuída, mas decorre do estigma e } \\
\text { do rebaixamento social delas (GALEOT- } \\
\text { TI, 2002). } \\
\text { Entender de modo igualitário as dife- } \\
\text { renças conduz a uma atitude de neutra- } \\
\text { lidade e indiferença que impede os a- } \\
\text { gentes de combater obstáculos que im- } \\
\text { pedem a inclusão de minorias no domí- } \\
\text { nio público (como cidadãos igualmente } \\
\text { dignos de respeito) e na sociedade (co- } \\
\text { mo parceiros sociais com iguais chances } \\
\text { de usufruir de oportunidades, prestígio } \\
\text { e bens) (GALEOTTI, 2002; FRASER, } \\
\text { 2003). }\end{array}$ \\
\hline
\end{tabular}




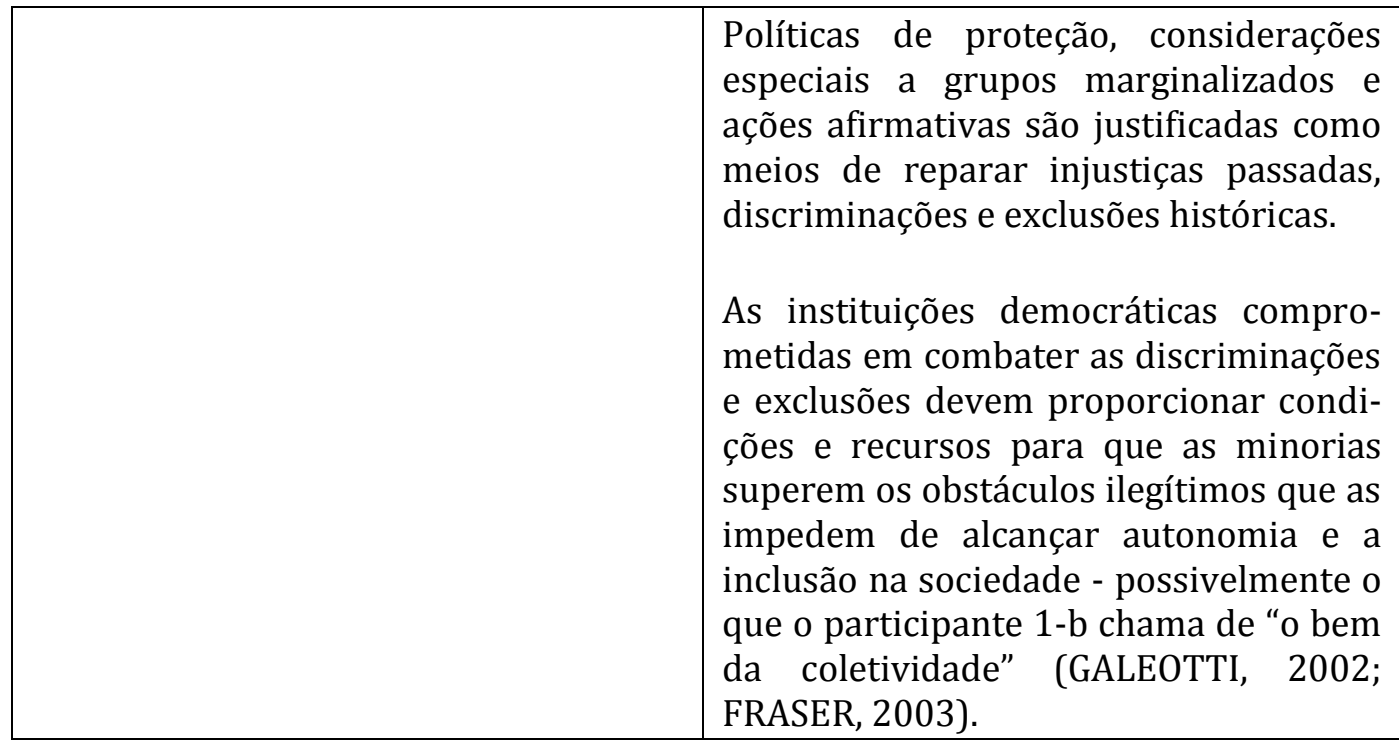

Fonte: MARQUES (2011, doc. eletrônico).

Diferentemente do YouTube, os participantes nos blogs procuram se posicionar frente a questões de interesse comum, negociar e refinar suas opiniões. Nesse ambiente, os usuários se esforçam por produzir e reproduzir razões potencialmente aceitáveis aos demais - o que é crucial para que eles se eduquem mutuamente sobre as regras da coexistência cívica com pessoas de origem e grupos distintos. A combinação de respeito mútuo e engajamento discursivo permite criar um espaço compartilhado, a fim de que os interlocutores possam buscar transformar interpretações sobre o valor concedido uns aos outros e as formas de tratamento recíproco.

\section{Facebook}

O Facebook é caracterizado como uma rede social para manter relacionamentos sociais previamente estabelecidos, com pessoas com quem se tem alguma conexão off-line - no círculo de amigos, da família, da escola, do trabalho, etc. (HARGITTAI; HSIEH, 2011; ELLISON et al., 2011). O Facebook também facilita, em menor grau, relações com pessoas que o usuário não conhece, mas que compartilham alguma conexão numa rede de amigos mútuos (BOYD; ELLISON, 2007; GRASMUCK; MARTIN; ZHAO, 2009, p. 5). 0 caráter de identificabilidade é destacado como um importante fator para que as pessoas sejam mais "realistas e honestas" nesta plataforma. 0 Facebook oferece às pessoas um conjunto de recursos - desde ferramentas visuais até técnicas descritivas e narrativas - para a auto-apresentação e a expressão de seus pertencimentos, sem a interferência de mediadores. A possibilidade de blo- 
quear o acesso de certos usuários a determinadas partes de suas contas permite que as pessoas se apresentem diferentemente para audiências distintas.

Cabe ressaltar que as pessoas no Facebook tendem a se expressar em tom privado, no sentido pessoal-íntimo. Os comentários, ao serem compartilhados publicamente, sinalizam o vínculo que o indivíduo mantém com seu grupo privado; e a demonstração pública de afeto indica um conjunto de escolhas privadas feitas por cada usuário. Esta propriedade do Facebook levou O'Sullivan (2005) a descrever os posts nesta plataforma como "comunicações pessoais de massa" (masspersonal communications). Nas palavras de Zizi Papacharissi (2010, p. 143), os usuários do Facebook "delineiam um espaço privado num domínio público". Sherri Grasmuck, Jason Martin e Shanyang Zhao (2009, p. 175), ao analisarem as trocas comunicativas entre membros de distintos grupos étnico-raciais, destacam que os usuários "parecem sempre falar para outros membros de seu próprio grupo étnico-racial, sinalizando solidariedade, ao invés de se dirigirem a observadores externos ao grupo". Estudos sobre expressões visuais no Facebook mostram que os usuários tendem a escolher cuidadosamente as imagens dispostas na galeria de fotos, sendo que os comentários nos murais permitem uma conversação com indivíduo, o qual é visto em relação a seu grupo social (ANDREW; PAPACHARISSI, 2011, p. 266). Também pesquisas sobre a construção de percepções que uns fazem dos outros nesta plataforma evidenciam que os "profiles" dos amigos, mais que o próprio "profile", afetam o modo pelo qual os usuários são percebidos pelos demais (WALTHER et al., 2009).

Nossa análise de dois ambientes no Facebook - uma página a favor de Bolsonaro (comunidade não oficial "Jair Bolsonaro") e um evento "Evento Fora Bolsonaro!" corrobora estudos que indicam que as interações no Facebook reforçam visões comuns, compartilhadas no grupo. Diferentemente do ambiente textual do YouTube e dos blogs, as pessoas no Facebook tendem a ficar menos expostas a conflitos de perspectivas, valores e opiniões. Isso não quer dizer que não ocorra divergências e discussões entre as pessoas no Facebook, já que nosso estudo não focalizou páginas de aceso restrito (KIM, 2011).

$\mathrm{Na}$ página a favor de Bolsonaro - com 1.746 participantes -, os participantes salientam seus valores em prol da família e do que consideram bons costumes, de modo congruente com os discursos expressos pelo deputado. Os comentários apresentam, geralmente, argumentos para defender a liberdade de expressão e para justificar que as pessoas "não são obrigadas a aceitar" as minorias. O evento "Evento Fora Bolsonaro" registrou 43.808 participantes. Neste ambiente, os participantes demandam o 
compartilhamento de informações sobre o caso, num claro esforço para sensibilizar o círculo de pessoas conhecidas dentro da rede de conexões ${ }^{2}$. Reivindicam, também, ações para mobilizar mais amplamente a sociedade e chamar a atenção dos media massivos: (“DIVULGUEM ESSE EVENTO, MANDEM EMAILS E CARTAS PARA JORNAIS E REVISTAS!”).

Nos dois espaços analisados no Facebook, a solidariedade intra-grupo e a hostilidade contra quem pensa diferente parecem reforçar mutuamente a confiança da coletividade de que suas escolhas são corretas, não sendo preciso negociar suas preferências e identidades com aqueles que têm visões opostas (ELLISON; STEINFIELD; LAMPE, 2011; CONROY; FEEZELL; GUERRERO, 2012). Ao se verem expostos a valores e opiniões conflitantes, os membros do Facebook, ao invés de escutarem atentamente os oponentes e se engajarem na troca argumentativa para defender as suas posições, buscam, ao invés disso, expulsar os "intrusos", como se pode ver no Quadro 6.

Quadro 6 - Expressões de Intolerância no Facebook

Participante 1-d: "se vc NÃO CURTE cai fora!";

Participante 2-d:"Mara, por que você não sai daqui? Todos são a favor do Bolsonaro aqui. Você é "intrusa"! Vá para a "oposição" e deixe-nos em paz."

Participante 3-d : "Janete, é lamentável ler essas coisas. Sai daqui que você não é bem vinda... Essa pagina é dele e aqui todos estao a favor dele! Tirando algumas imbecis como você."

$$
\text { Fonte: FACEBOOK (2011a, doc. eletrônico). }
$$

As poucas pessoas que contestaram as ideias da maioria tendem a ser desqualificadas e, não raro, ofendidas. Na página de Jair Bolsonáro, a ausência de mediação no Facebook para barrar o acesso de pessoas com opiniões e perspectivas diferentes é lamentada por um participante ("só quem é apoiador de Bolsonaro poderia estar interagindo nas postagens, essa seria a moderação pretendida"). Na página do "Evento Fora Bolsonaro", uma pessoa que se manifestou a favor da declaração do deputado foi acusada de "fake" e convidada a se retirar daquele ambiente - sendo-lhe indicado um link de um grupo a favor do deputado ("Tem pessoas que pensam como você. Junte-se a elas apoiando quem você bem entender.").

No Facebook, os cidadãos se mostram mais propriamente envolvidos em mobilizações do que em discussões com os seus oponentes. Embora obviamente importante para a ação política, a mobilização é frequentemente incompatível com a discussão política (MUTZ,

\footnotetext{
2 Os usuários compartilham links que contextualizam a polêmica, oferecem informações sobre racismo e homofobia, divulgam petições públicas e leis. Há indicação de links para identificar pessoas e grupos sociais que apoiam o deputado; textos jornalísticos que noticiam medidas legais tomadas pela $\mathrm{OAB}$ para processar Bolsonaro e, ainda, textos para identificar parlamentares a favor e contra o deputado.
} 
2006, p. 125). Nesse sentido, o Facebook incrementa a habilidade dos cidadãos ordinários expressarem e documentarem suas preferências. A grande adesão ao "Evento Fora Bolsonaro", com 43.808 participantes, contra 1.746 participantes na página Pró-Bolsonaro, mostra que os usuários querem ser reconhecidos e valorizados como alguém que condena a discriminação. Para além de um mero "slacktivism" ou "clicktivism", os adeptos do "Evento" constroem um gesto público de repúdio às declarações do deputado, o qual envolve não apenas aqueles que foram vítimas da injúria (negros e gays), mas, sim, todos os que condenam a discriminação e a falta de respeito na sociedade.

Ainda que essas mobilizações, como tantas outras desencadeadas no ambiente online, não se estruturem como uma prática contínua de engajamento cívico - seja porque não suscitam reflexão mais aprofundada em prol de uma determinada causa, seja, ainda, porque não implicam em custos necessários para garantir maior potência política (MOROZOV, 2011) - elas têm a potência política de "despertar a consciência num ambiente comunitário", sendo difícil suprimir tais trocas espontâneas (PAPACHARISSI; OLIVEIRA, 2012, p. 208, ver também TUFEKCI; WILSON, 2012, p. 376; DOUAI; NOFAL, 2012). Nossas análises do "Evento Fora Bolsonaro" e da página "Jair Bolsonaro" mostram que a solidariedade entre participantes de grandes grupos homogêneos pode ser usada tanto para combater a discriminação quanto para fomentar a intolerância; para motivar ações que reconhecem direitos de certos grupos em desvantagem quanto para desencadear ações que questionam ou negam esse reconhecimento.

\section{Conclusão: sobre a ecologia complexa das redes sociais online}

Neste artigo, buscamos lançar luz sobre a conectividade das redes online em sua ecologia complexa. Esta perspectiva contribui para aguçar nossa atenção para uma série de questões. A primeira, conceber o processo comunicativo de maneira mais global no ambiente digital permite entender as especificidades das plataformas online. Em nosso estudo, notamos diferentes padrões de interação comunicativa em torno do episódio Preta Gil e Bolsonaro em cada ambiente selecionado. No YouTube - um ambiente aberto ao público e, em grande parte, anônimo, no qual geralmente se fala para uma "massa de usuários ordinários imaginados" (BURGESS; GREEN, 2009, p. 8) - as pessoas e os grupos manifestaram espontânea e veementemente suas visões, com óbvio sacrifício da tolerância política; e expressaram ofensas sem constrangimentos. Nos blogs - um ambiente no qual as interpretações usualmente se dão em tom pessoal tal como num "púlpito público" (PAPACHARISSI, 2010, p. 
145), as pessoas se engajaram discursivamente umas com as outras. No "Papo de Homem" a discussão se deu num ambiente com visões divergentes e no Blog Lola, entre pessoas com posicionamentos e perspectivas semelhantes. Em ambos, os interlocutores se importaram em justificar suas posições e demonstraram respeito para com seus outros potenciais interlocutores. Já no Facebook - um ambiente comunitário, no qual frequentemente se expressa mediante "comunicações pessoais de massa" (O'SULLIVAN, 2005), as pessoas tenderam a reafirmar suas preferências e evitaram entrar em discussões com pessoas "do outro lado".

Em segundo, adotar uma abordagem mais ampla do ambiente virtual permite-nos indagar sobre as conexões que se estabelecem entre diferentes plataformas e a configuração de práticas democráticas. Nosso estudo mostra que os ambientes podem apresentar lógicas díspares ou mesmo antagônicas. Por exemplo, ao observar a ofensa verbal e a hostilidade recíproca demonstrada pelos usuários no YouTube, podemos construir a imagem de uma sociedade dividida, em que as diferenças em termos de raça e de orientação sexual restringem drasticamente o diálogo entre os sujeitos. Já nos blogs, ao observar a disposição dos usuários em considerar seus interlocutores como parceiros de igual status, a fim de justificar suas preferências e trocar argumentos diante do desacordo moral e do conflito de interesses, podemos construir a imagem de "cidadãos deliberativos". Estes se mostram empenhados em se educar mutuamente a respeito das regras de convivência cívica com pessoas diferentes. A maior adesão dos usuários do Facebook ao "Evento Fora Bolsonaro" (43.808 confirmações de presença), em relação à da Página Jair Bolsonaro (1.746 curtidas) sugere cidadãos engajados numa notável mobilização contra o racismo, embora eles rejeitassem discutir com pessoas do 'outro lado'. Portanto, para entender como os cidadãos processam os conflitos sociais e negociam suas opiniões não basta que o pesquisador observe a comunicação em um único espaço ou dispositivo isolado.

Em terceiro, adotar uma visão mais ampla de diferentes ambientes de media permitenos cruzar dados, a fim de ampliar nossa interpretação e explicação dos fenômenos. Nosso estudo mostra, endossando o argumento de Mutz (2006), que o engajamento discursivo e o ativismo político não caminham necessariamente juntos em um mesmo domínio. No contexto do blog Papo de Homem, os usuários demonstram alto nível de engajamento discursivo, mas o ativismo político foi reduzido. Já no Facebook, os usuários apresentam baixo grau de troca argumentativa, mas alto grau de ativismo político. Contudo, um exame cuidadoso permite notar ambientes híbridos. Os participantes do blog feminista "Lola" demonstram tanto engajamento discursivo quanto ativismo político. 
Apesar do ambiente complexo para a conectividade online, com produção de informação descentralizada e a disseminação de conteúdo, nosso estudo sugere que há uma "divisão de tarefas" nesse ambiente, em que a combinação de designs e regras de interação configuram as expressões e as trocas comunicativas. Os cidadãos, por exemplo, podem se engajar em discussões em blogs, no caso, para negociar suas opiniões com oponentes e refinar seu conhecimento político sobre alternativas. Podem ainda buscar interagir com aqueles que pensam semelhante em blogs ativistas ou de comunidades de interesses comuns. Podem, simultaneamente, postar comentários jocosos e sarcásticos no YouTube e trocar ofensas com adversários. Podem, ainda, promover mobilização e ativismo político no Facebook. Obviamente, é sempre uma tarefa mais complexa apreciar as implicações dessas diferentes práticas comunicativas para a negociação do conflito entre membros de distintos grupos sociais, tendo em vista seus efeitos para a democracia num contexto mais amplo. Contudo, observar a ecologia complexa dos media e a conectividade em rede permite que façamos inferências mais nuançadas sobre as práticas comunicativas em diversas situações.

\section{Referências}

ANDREW, Mendelson; PAPACHARISSI, Zizi. Look at us: collective narcissism in college student Facebook photo galleries. In: PAPACHARISSI, Zizi (Ed.). A networked self: identity, community and culture on social network sites. New York: Routledge, 2011. p. 251-273.

APOCALYPSEFORFREE. Bolsonaro detona gays, negros e Preta Gil em favor da familia [sic]. [São Paulo, 2011]. Disponível em: <http://www.youtube.com/watch?v=y8imZAGzO_c $>$. Acesso em: 9 set. 2015.

ARONOVICH, Lola. Bolsonaro e seu nicho de mercado reaça. In: ARONOVICH, Lola. Escreva Lola Escreva. [S.I.], 2011. Disponível em:

<http://escrevalolaescreva.blogspot.com.br/2011/03/bolsonaro-e-seu-nicho-de-mercadoreaca.html>. Acesso em: 9 set. 2015.

BÄCHTIGER, André et al. Disentangling diversity in deliberative democracy: competing theories, their blind spots and complementarities. Journal of Political Philosophy, Oxford, v. 18, p. 32-63, 2010.

BOU-FRANCH, Patricia; LORENZO-DUS, Nuria; BLITVICH, Pilar Garcés-Conejos. Social interaction in YouTube text-based polylogues: a study of coherence. Journal of ComputerMediated Communication, Bloomington, v. 17, p. 501-521, 2012.

BOYD, Danah; ELLISON, Nicole. Social network sites: definition, history, and scholarship. Journal of Computer-Mediated Communication, Bloomington, v. 13, p. 210-230, 2007.

BURGESS, Jean; GREEN, Joshua. YouTube: online video and participatory culture. 
Cambridge, MA: Polity Press, 2009.

CITRON, Danielle Keats. Civil rights in our information age. In: LEVMORE, Saul; NUSSBAUM, Martha. The offensive internet: speech, privacy, reputation. Cambridge, MA: Harvard University Press, 2010, p. 31-49.

CONROY, Meredith; FEEZELL, Jessica; GUERRERO, Mario. Facebook and political engagement: a study of online political group membership and offline political engagement. Computers in Human Behavior, Amsterdam, v. 28, p. 1535-1546, 2012.

DOUAI, Aziz; NOFAL, Hala. Commenting in the online arab public sphere: debating the Swiss Minaret Ban and the "ground zero mosque" online. Journal of Computer-Mediated Communication, Bloomington, v. 17, p. 266-282, 2012.

ELLISON, Nicole et al. With a little help from my friends: how social network sites affect social capital processes. In: PAPACHARISSI, Zizi (Ed.). A networked self: identity, community and culture on social network sites. New York, NY: Routledge, 2011. p. 124-145.

ELLISON, Nicole; STEINFIELD, Charles; LAMPE, Cliff. Social capital implications of Facebookenabled: communication practices. New Media Society, Chicago, v. 13, n. 6, p. 873-892, 2011.

FACEBOOK. Página Jair Bolsonaro. 2011a.

FACEBOOK. Evento Fora Bolsonaro. 2011b.

FRASER, Nancy. Social justice in the age of identity politics: redistribution, recognition, and participation. In: FRASER, Nancy; HONNETH, Axel (Ed.). Redistribution or recognition: a political-philosophical exchange. Nova York, NY: Verso, 2003. p. 7-109.

FORST, Rainer. "To tolerate means to insult". Toleration, recognition and emancipation. In: VAN DEN BRINK, Bert; OWEN, David. Recognition and power: Axel Honneth and the tradition of social critical theory. New York: Cambridge University, 2007. p. 215-237.

GALEOTTI, Anna Elisabetta. Toleration as recognition. Cambridge: Cambridge University, 2002.

GIL, Preta. Preta Gil. 2011. Disponível em: <https://twitter.com/pretagil >. Acesso em: 29 mar. 2011.

GRASMUCK, Sherri; MARTIN, Jason; ZHAO, Shanyang. Ethno-racial identity displays on Facebook. Journal of Computer-Mediated Communication, Bloomington, v. 15, n. 1, p. 158-188, 2009.

HABERMAS, Jürgen. Between facts and norms. Cambridge: MIT, 1996.

HARGITTAI, Eszter; HSIEH, Yu-li Patrick. From dabblers to omnivores: a typology of social network site usage. In: PAPACHARISSI, Zizi (Ed.). A networked self: identity, community and culture on social network sites. New York: Routledge, 2011. p. 146-168. 
HARTLEY, John. Uses of YouTube: digital literacy and the growth of knowledge. In: BURGESS, Jean; GREEN, Joshua (Ed.). YouTube: online video and participatory culture. Cambridge: Polity, 2009. p. 126-143.

HILL, Kevin A.; HUGHES, John E. Cyberpolitics: citizen activism in the age of the internet. Lanham: Rowman \& Littlefield, 1998.

JENKINS, Henry. What happened before YouTube. In: BURGESS, Jean; GREEN, Joshua (Ed.). YouTube: online video and participatory culture. Cambridge: Polity, 2009. 109-125.

JURIS, Jeffrey. Violence performed and Imagined: militant action, the black bloc, and the mass media in Genoa. Critique of Anthropology, Manchester \& Londres, v. 25, n. 4, p. 413432, 2005.

KAYE, Barbara. Between Barack and a net place: users and uses of social network sites and blogs for political information. In: PAPACHARISSI, Zizi (Ed.). A networked self: identity, community and culture on social network sites. New York: Routledge, 2011. p. 208-231.

KIES, Raphaël. Promises and limits of web-deliberation. Nova York: Palgrave Mcmillan, 2010.

KIM, Yonghwan. The contribution of social network sites to exposure to political difference: the relationships among SNSs, online political messaging, and exposure to cross-cutting perspectives. Computers in Human Behavior, Amsterdam, v. 27, p. 971-977, 2011.

MAIA, Rousiley Celi Moreira. From public sphere to deliberative system: locating the place of the media. In: MAIA, Rousiley Celi Moreira. Deliberation, the media and political talk. New York: Hampton, 2012. p. 59-76.

MAIA, Rousiley Celi Moreira. Recognition and the Media. Nova York: Palgrave McMillan, 2014.

MARQUES, Flaco. Bolsonaro, meu bom. In: PAPO de Homem. [S.l.], 2011. Disponível em: <http://papodehomem.com.br/bolsonaro-meu-bom/>. Acesso em: 9 set. 2015.

MANSBRIDGE, Jane et al. A systemic approach to deliberative democracy. In: PARKINSON, John; MANSBRIDGE, Jane (Ed.). Deliberative systems. Cambridge: Cambridge University, 2012. p. 1-26.

MOROZOV, Evgeny. The net delusion: the dark side of internet freedom. New York: PublicAffairs, 2011.

MUTZ, Diana. Hearing the other side: deliberative versus participatory democracy. Cambridge: Cambridge University, 2006.

O'SULLIVAN, Patrick. Masspersonalcommunication: rethinking the mass interpersonal divide. In: THE ANNUAL MEETING OF THE INTERNATIONAL COMMUNICATION ASSOCIATION, 2005, New York. Disponível em:

$<$ http://www.academia.edu/3768497/Web_as_a_medium_of_masspersonal_communication >. Acesso em: 10 ago. 2012. 
PAPACHARISSI, Zizi. A private sphere: democracy in a digital age: digital media and society series. Cambridge: Polity Press, 2010.

PAPACHARISSI, Zizi; OLIVEIRA, Maria de Fatima. Affective news and networked publics: the rhythms of news storytelling on \#Egypt. Journal of Communication, Seatle, v. 62, p. 266282, 2012.

PETTIT, Philip. Deliberative democracy, the discursive dilemma, and republican theory. In: FISHKIN, James; LASLETT, Peter (Ed.). Debating deliberative democracy: philosophy, politics and society. Malden: Blackwell, 2003. p. 138-162.

RECUERO, Raquel. Fluxos de informação e capital social nos weblogs. In: STEFFEN, Cesar; POZENATO, Kenia M. (Org.). Mídia, cultura e contemporaneidade. Caxias do Sul: EDUCS, 2010. p. 117-142.

RECUERO, Raquel; AMARAL, Adriana; MONTARDO, Sandra. Blogs: mapeando um objeto. In: AMARAL, Adriana; RECUERO, Raquel; MONTARDO, Sandra (Org.). Blogs.com: estudos sobre blogs e comunicação. São Paulo: Momento, 2009. p. 27-54.

ROCHA, Marcela. Bolsonaro: Meu filho não namoraria Preta Gil por causa do comportamento dela. Terra Magazine por Bob Fernandes, São Paulo, 29 mar. 2011. Disponível em: <http://terramagazine.terra.com.br/interna/0,,OI5034595-EI6578,00Bolsonaro+Meu+filho+nao+namoraria+Preta+Gil+por+causa+do+comportamento+dela.htm l>. Acesso em: 9 set. 2015.

ROWE, Ian. Civility 2.0: a comparative analysis of incivility in online political discussion. Information, Communication \& Society, July 2014. Disponível em: http://www.tandfonline.com/doi/abs/10.1080/1369118X.2014.940365\#.VcygBvlVhBc. Acesso em: 13 ago. 2015.

TREMAYNE, Mark. Harnessing the active audience: synthesizing blog research and lessons for the future of media. In: TREMAYNE, Mark (Ed.). Blogging, citizenship and the future of media. New York: Routledge, 2007. p. 261-272.

TUFEKCI, Zeynep; WILSON, Christopher. Social media and the decision to participate in political protest: observations from Tahrir Square. Journal of Communication, Seattle, v. 62, p. 363-379, 2012.

WALTHER, Joseph et al. Interaction of interpersonal, peer, and media influence sources online: a research agenda for technology convergence. In: PAPACHARISSI, Zizi (Ed.). A networked self: identity, community and culture on social network sites. New York: Routledge, 2011. p. 17-38.

WALTHER, Joseph et al. Self-generated versus other-generated statements and impressions in computer-mediated communication: a test of warranting theory using Facebook.

Communication Research, Thousand Oaks, v. 36, p. 229-253, 2009.

YOUNG, Iris. Inclusion and democracy. Oxford: Oxford University, 2000. 


\title{
Democracy and complex ecology of online social networking sites: an investigation of discussions on racism and homophobia
}

\begin{abstract}
This article aims at examining the complex ecology of online communication. While most studies on digital communication investigates specific platforms or particular forums, this study examines the impact of a controversial event - the racist and homophobic expressions of the Federal Congressman Jair Bolsonaro in the CQC TV Show - in three environments: YouTube, blogs and Facebook. The analysis explores how citizens, through daily online conversation, exchange their views and perspectives, negotiate the value and the treatment they dispense to each other. The results reveal the characteristics of social conflict regarding the rules of civic coexistence in these platforms, with distinct designs and affordances as well as different expectations of interaction between users and audiences.
\end{abstract}

\section{Keywords}

Deliberation. Racism. Homophobia. Blog. Facebook. YouTube.

Recebido em 14/08/2015

Aceito em 03/12/2015 